\title{
The Effect of Peptide Treatment on the HLA-Binding and Antibody Production in Peripheral Blood Mononuclear Cells Obtained from Japanese Breast Cancer Patients
}

Banri Tsuda $^{1 *}$, Yoshie Kametani ${ }^{2}$, Asuka Miyamoto ${ }^{1}$, Hirohito Miyako ${ }^{3}$, Nobue Kumaki ${ }^{4}$, Rin Ogiya ${ }^{1}$, Risa Oshitanai ${ }^{1}$, Mayako Terao $^{1}$, Toru Morioka ${ }^{1}$, Naoki Niikura ${ }^{1}$, Takuho Okamura ${ }^{1}$, Yuki Saito ${ }^{1}$, Yasuhiro Suzuki ${ }^{1}$ and Yutaka Tokuda ${ }^{1}$

${ }^{1}$ Department of Breast and Endocrine Surgery, Tokai University School of Medicine, Japan

${ }^{2}$ Department of Immunology, Tokai University School of Medicine, Japan

${ }^{3}$ Department of Surgery, Niwa Hospital, Japan

${ }^{4}$ Department of Pathology, Tokai University School of Medicine, Japan

"Corresponding author: Banri Tsuda, Department of Breast and Endocrine Surgery, Tokai University School of Medicine, 143 Shimokasuya, Isehara-shi, Kanagawa, Japan, Tel: 0463-93-1121; E-mail: isd_g@hotmail.com

Received date: 23 December 2014; Accepted date: 11 February 2015; Published date: 16 February 2015

Copyright: (C) 2015 Tsuda B, et al. This is an open-access article distributed under the terms of the Creative Commons Attribution License, which permits unrestricted use, distribution, and reproduction in any medium, provided the original author and source are credited.

\begin{abstract}
Background: Our previous predictive peptide binding studies indicated that a novel 20-mer multiple antigen peptide, CH401MAP, containing an anti-human epidermal growth factor receptor 2 (HER2) monoclonal antibody epitope (N163-182), may potentially bind to more than 95\% of class I human leukocyte antigens (HLAs) and to $30-50 \%$ of class II HLAs expressed on peripheral blood mononuclear cells (PBMCs). In this study, CH401MAP was used for in vitro stimulation of PBMCs obtained from Japanese breast cancer patients, and anti-CH401MAP antibody secretion was evaluated.
\end{abstract}

Methods: PBMCs of breast cancer patients were stimulated with CH401MAP peptide in vitro. Eight days after stimulation, the culture supernatants were collected and the anti-CH401MAP antibody levels were determined using enzyme-linked immunosorbent assay. The correlation of the antibody level and HER2 expression level after in vitro stimulation was also evaluated.

Results: CH401MAP specific antibody was detected in the culture supernatants of patients' PBMCs after in vitro culture, irrespective of the peptide stimulation. The antibody levels of the three patient's groups were significantly higher than that of HD group. Significant correlation was not observed between specific antibody production and cancer progression.

Conclusion: The PBMC of Japanese breast cancer patients possessed the potential of anti-CH401MAP antibody secretion. The antibody secretion level was significantly higher than that of $\mathrm{HD}$. It is correlated with the expression of HER2 on the cancer tissues but not with the HER2 level in the sera of patients.

Keywords: Human epidermal growth factor receptor 2 (HER2); Breast cancer; Anti-HER2 antibody; CH401; Peptide vaccine

\section{Introduction}

In previous decades, numerous attempts have been made to develop therapeutic peptide vaccines for cancer [1]. Several peptide vaccines have been developed to induce anti-tumor immune responses in breast cancer patients [2]. In order to induce an effective T-cell mediated immune response against breast cancer, the vaccine peptide must anchor onto the human leukocyte antigen (HLA) molecules of the antigen presenting cells [3]. Thus, the HLA types of patients may determine the vaccine efficacy [4]. The human epidermal growth factor receptor 2 (HER2) peptide breast cancer vaccines contain partial sequences of HER2 that can induce peptide-specific cytotoxic $\mathrm{T}$ lymphocytes (CTLs), which recognize and eliminate tumor cells $[5,6]$. However, the peptide specificity to major HLA types renders the vaccine ineffective in individuals that do not express the predominant HLA types [7]. In addition, there is considerable variation in HLA expression among various races. Thus, peptide vaccines specific for HLA types commonly expressed in Caucasians may not be effective for treating Japanese breast cancer patients. Moreover, most peptidebased vaccines do not effectively stimulate both helper and killer $\mathrm{T}$ cells. In addition, peptide vaccines that use chemically synthesized peptides with epitopes for both helper and killer cells have been shown to cause side effects [8]. Therefore, the development of a breast cancer vaccine with natural peptides have binding specificity to the HLA molecules that are predominantly expressed in Japanese patients and that can stimulate both helper and killer $\mathrm{T}$ cells is required.

In this study, we used a novel HER2 peptide containing a B-cell epitope that can induce anti-tumor effects in a mouse system [9]. We previously determined that the N: 163-182 epitope of the CH401 monoclonal antibody (mAb) was crucial for stimulating B cells [9]. Therefore, the aforementioned epitope sequence was used to synthesize the peptide, CH401MAP, used in this study. In a previous study, we showed that CH401MAP has moderate to high affinity for HLA types expressed in Japanese breast cancer patients. Furthermore, we previously performed in vitro studies with peripheral blood 
Citation: Tsuda B, Kametani Y, Miyamoto A, Miyako H, Kumaki N, et al. (2015) The Effect of Peptide Treatment on the HLA-Binding and Antibody Production in Peripheral Blood Mononuclear Cells Obtained from Japanese Breast Cancer Patients. J Vaccines Vaccin 6: 270. doi:10.4172/2157-7560.1000270

Page 2 of 8

mononuclear cells (PBMCs) obtained from Japanese breast cancer patients and showed that CH401MAP stimulates lymphocyte proliferation and IL-2 production and increases $\mathrm{CD} 4^{+}$and $\mathrm{CD} 8^{+}$cell numbers. The study also indicated that the peptide activated $\mathrm{CD} 4^{+}$ cells and increased the $\mathrm{CD} 8^{+}$cell numbers of the breast cancer patient groups with low, moderate, or high HER2 expression and that the proliferation ability of cells of the patient groups was significantly higher than that of the healthy donor (HD) group.

Miyako et al demonstrated that CH401MAP vaccination reduces HER2 overexpressing A20 tumor in mice [9]. Moreover, Kametani et al. showed that CH401MAP induces antibody production in a humanized mouse system [10]. In this study, we performed in vitro stimulation studies using CH401MAP and PBMCs from breast cancer patients and HDs and assessed the secreted anti-CH401MAP antibody levels in relation to HER2 expression.

\section{Material and Methods}

\section{Patients}

We enrolled breast cancer patients and HDs by obtaining informed consent using a protocol approved by the Tokai University Hospital Institutional Review Board. Women aged 20 years or older with no history of malignant disease in the past and with histologically confirmed breast cancer before their surgery were enrolled at Tokai University Hospital, Kanagawa, Japan in the period between Jan 2010 and July 2012

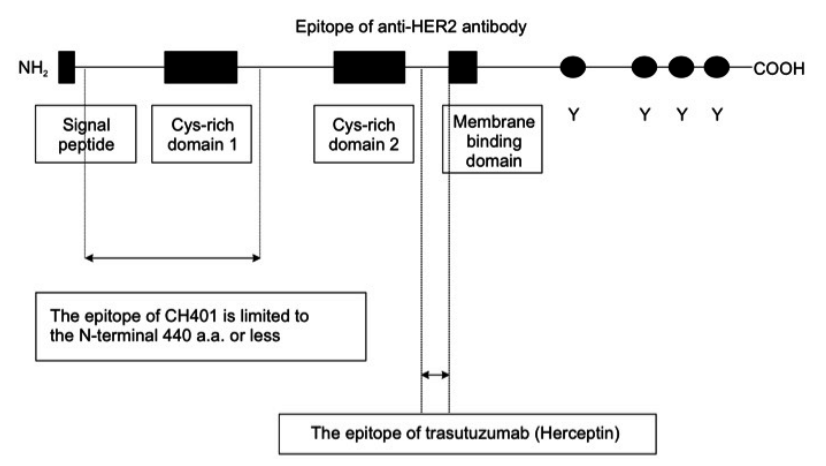

Figure 1: CH401MAP synthetic peptides. The epitope of $\mathrm{CH} 401$ is limited to the N:163-182(ILWKDIFHK). CH401MAP; (YQDTILWKDIFHKNNQLALT-BBB) 8-K4K2KB CH401MAP located near $\mathrm{N}$ terminus is different from trastuzumab binding site near transmembrane.

\section{CH401MAP peptide}

The peptide used for the in vitro stimulation studies was prepared as described previously [9]. Briefly, the 20-mer peptide containing the epitope of CH401 anti-HER2/neu antibody used in this study was previously developed by Ishida et al. The peptide sequence consisted of 20 amino acids (N:163-182, YQDTILWKDIFHKNNQLALT). The multiple antigen peptide (MAP) was synthesized from Rink amide resin (0.4-0.7 mmol/g) using a peptide synthesizer ACT357 (Advanced ChemTech, Louisville, KY, USA), resulting in the formation of amide at the carboxyl termini (Figure 1). These MAPs were used for the subsequent stimulation studies and enzyme-linked immunosorbent assay (ELISA) studies.

\section{HLA typing and predictive peptide-MHC binding affinity analysis}

For HLA typing, $1.5 \mathrm{ml}$ of blood was used. Genotyping of the HLA$\mathrm{A}, \mathrm{B}$, and DRB1 alleles was performed using the PCR-SSOP Luminex method with LABType SSO (One Lambda Inc., Canoga Park, CA, USA), a reverse SSO DNA typing system, according to the manufacturer's instructions. A flow analyzer, LABScanTM 100, identified the fluorescent intensity of Phycoerythrin (PE) on each microsphere. The determination of the HLA allele was based on the reaction pattern compared to patterns associated with published (http://www.hla.or.jp/) HLA allele sequences, which included all HLA allele types that are known until now. The analysis was performed with HLA Fusion (One Lambda Inc.).

The following databases were used for predicting the CH401MAP peptide affinity to HLA molecules: SYFPEITHI database for MHC ligands and MHC-binding peptides developed by Rammensee H. G. et al. (http://www.syfpeithi.de/; [11]; BioInformatics and Molecular Analysis Section (BIMAS) developed by Parker K. C. et al. (http:// www-bimas.cit.nih.gov/molbio/hla_bind/; [12] for predicting peptides that bind to HLA class I; and Immune Epitope Database (IEDB) and analysis resource developed by Peters B. et al. (http:// www.immuneepitope.org/ [13] for predicting peptides that bind to HLA class II molecules.

\section{Immunohistochemistry}

The HER2 expression level score was estimated in the main tumor by immunohistochemistry (IHC) using Dako Hercep Test II (Dako Japan, Japan, Tokyo) and fluorescence in situ hybridization (FISH), according to the manufacturer's instructions. Results of IHC and FISH were evaluated according to the criteria recommended by the manufacturer by using scores according to the ASCO/CAP guideline, only membrane staining intensity and pattern were evaluated using the 0-3+ scale as illustrated in the Dako Hercep Test II scoring guidelines ( 0 for no staining at all or membrane staining in less than $10 \%$ of the tumor cells; $1+$ for only partial, weak staining of the cell membrane of more than $10 \%$ of the tumor cells; $2+$ for moderate staining of the complete cell membrane in more than $10 \%$ of the tumor cells; $3+$ for intense staining of the complete membrane in more than $10 \%$ of the tumor cells). The analysis was performed by Nobue Kumaki who familiarized in the use of Hercep Test for breast cancer patients. In accordance with the Dako Hercep Test II guide, HER2 overexpression was assessed as negative for scores of 0 or $1+$ and positive for scores of $2+$ and $3+[14]$.

The patients were assigned to 3 groups based on HER2 expression as follows: (1) HER2 0 group, patients with HER2 expression IHC score of 0; (2) HER2 1+2+ group, patients with HER2 expression IHC scores of $1+$ or $2+$; and (3) HER2 $3+$ group, patients with HER2 expression IHC score of 3+. Healthy female donors without any malignant disease in the past were enrolled for the control group. Blood samples $(7.5 \mathrm{ml})$ were collected from patients by using Vacutainer ACD tubes (NIPRO Corporation, Japan, Osaka) on the morning of the day of surgery. 
Citation: Tsuda B, Kametani Y, Miyamoto A, Miyako H, Kumaki N, et al. (2015) The Effect of Peptide Treatment on the HLA-Binding and Antibody Production in Peripheral Blood Mononuclear Cells Obtained from Japanese Breast Cancer Patients. J Vaccines Vaccin 6: 270. doi: $10.4172 / 2157-7560.1000270$

Page 3 of 8

\section{In vitro PBMC stimulation with CH401MAP peptide}

The in vitro stimulation experimental setup is illustrated in Figure 2. The PBMCs were isolated from $6 \mathrm{ml}$ blood by performing density gradient centrifugation $\left(5,000 \times \mathrm{g}, 30 \mathrm{~min}, 20^{\circ} \mathrm{C}\right)$ by using FicollHypaque (SIGMA-ALDRICH, UK, London). The isolated PBMCs were suspended in phosphate-buffered saline (PBS) and centrifuged at $3,000 \times \mathrm{g}$ for $5 \mathrm{~min}$ at $4^{\circ} \mathrm{C}$. After performing cell enumeration, the cells were incubated with $500 \mu \mathrm{l}$ of RPMI 1640 medium supplemented with $10 \%$ human serum (heat inactivated at $55^{\circ} \mathrm{C}$ for $30 \mathrm{~min}$; Lonza, Walkersville, MD, USA), $1 \%$ l-glutamine, $1 \%$ sodium pyruvate, $1 \%$ non-essential amino acids, and $0.5 \%$ penicillin-streptomycin. The cell cultures were grown in 96 -well, round-bottom plates at $37^{\circ} \mathrm{C}$ in a $5 \%$ $\mathrm{CO}_{2}$ atmosphere. All samples were stimulated with $5 \mu \mathrm{g}$ peptides (100 $\mu \mathrm{g} / \mathrm{ml}$ ) within $12 \mathrm{~h}$. The detailed protocol for the in vitro culture of the PBMCs is shown in Figure 1. The stimulated cells were obtained from the 4 groups, HD, HER2 0 , HER2 $+1+2$, and HER2 $3+$, and $1 \times 105$ cells were used for flow cytometry (FCM) analysis. The remaining cells $(5 \times 105$ cells/well $)$ were plated and CH401MAP or PBS was added to the culture wells. The surface markers of the cells were analyzed 21 days after the start of stimulation.

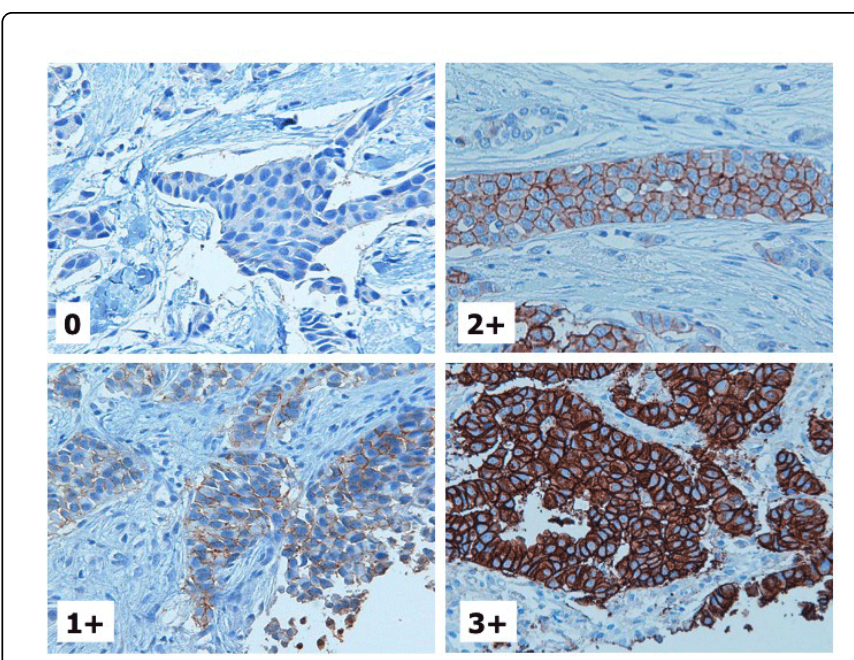

Figure 2: Examples with HER2 expression evaluation by IHC (Dako Herceptest II) on site of breast cancer.

\section{Immunofluorescence staining and FCM analysis}

The following antibodies were purchased from BioLegend Inc. (San Diego, USA): PE-conjugated anti-human CD4 mAbs (clone:L200), fluorescein isothiocyanate (FITC)-conjugated anti-human CD8 mAbs (clone:G42-8), peridinin chlorophyll protein complex with cyanin-5.5 (PerCP-Cy5.5)-conjugated anti-human CD3 mAbs (clone:HIT3a), allophycocyanin (APC)- conjugated anti-human CD25 mAbs (clone:M-A251), PE-conjugated anti-human CD4 mAbs (Clone:L200), PerCP-Cy5.5-conjugated anti-human CD3 mAbs (clone:M-A251), and FITC-conjugated anti-human CD25 mAbs (clone:BC96). The fixation/permeabilization concentrate, diluent, and permeabilization buffer were purchased from BD Biosciences (California, USA). Immunofluorescence staining was performed as reported previously [15]. Fluorescence intensity of fluorochrome-labeled cells was determined by FCM (FACSCalibur, BD Biosciences) with Cell Quest Pro version 0.3.ff2b (BD Biosciences). The final data analysis was performed using FlowJo version 7.6.1 (Tree Star, Inc.). All the data used for the analyses were acquired from the lymphocyte gate.

\section{Anti-CH401MAP antibody ELISA}

The concentrations of anti-CH401MAP antibodies were determined using ELISA. Sera were collected and stored at $-80^{\circ} \mathrm{C}$ until required for experimental analysis. For the ELISA, microplate wells were coated with CH401MAP $(1 \mathrm{mg} / \mathrm{ml})$ diluted in carbonate buffer $(\mathrm{pH}$ 9.5). Wells were washed with PBS-Tween $20(0.05 \% \mathrm{v} / \mathrm{v})$ and blocked with $3 \%$ bovine serum albumin-PBS at room temperature for $2 \mathrm{~h}$. Following three washes with PBS-Tween 20, serial dilutions of sera samples were added and the plates were incubated for $2 \mathrm{~h}$ at room temperature. Plates were washed three times and horseradish peroxidase (HRP)-conjugated goat anti-human IgG- antibody (BD Bioscience; 1:3000 v/v) was added. After 1.5-h incubation at room temperature, plates were washed and TMB peroxidase EIA substrate kit solution (Bio-Rad Laboratories, Hercules, CA, USA) was added. Reaction was stopped by adding $2 \mathrm{~N} \mathrm{H} 2 \mathrm{SO} 4$ and the absorbance was determined at $450 \mathrm{~nm}$ by using SPECTRAmax250 (Molecular Devices, Japan, Tokyo). For epitope mapping, CH401 Mab was used as the primary antibody instead of antisera. For the assay for determining the antibody class of anti-CH401MAP antibody, HRP-conjugated antibodies against IgM or IgG were used as secondary antibodies (BD Biosciences).

\section{Statistical analyses}

Statistically significant differences in antibody secretion by healthy donors and breast cancer patients were determined using two-tailed Student's $\mathrm{t}$ test. Values of $\mathrm{p}<0.05$ were considered statistically significant. Results are displayed as mean \pm Standard Deviation (SD).

\begin{tabular}{|l|l|l|}
\hline Patients & \multicolumn{2}{l|}{$n=31$} \\
\hline & Range & Mean (median) \\
\hline Age & $26-75$ & $54 \pm 13(51)$ \\
\hline DCIS/IDC/ILC & $9 / 21 / 1$ \\
\hline HER2 0/1+,2+/3+ & $11 / 8 / 12$ \\
\hline LN meta pN0/pN1 & $27 / 4$ \\
\hline Healthy Donor & $n=11$ & \multicolumn{2}{|l}{} \\
\hline & Range & Mean (median) \\
\hline Age & $21-42$ & $31 \pm 7.7$ (29) \\
\hline
\end{tabular}

Table 1: clinical characteristics.

\section{Results}

\section{Demographics and clinical characteristics of study subjects}

Thirty-one breast cancer patients and 11 HDs were enrolled for this study. The mean ages of the patients and HDs were $54 \pm 13$ years and $31 \pm 7.7$ years, respectively. The breast cancer patient histology characteristics were as follows: 9 ductal carcinoma in situ (DCIS); 21 invasive ductal carcinoma; and 1 invasive lobular carcinoma. Based on the HER2 expression data (Figure 3), 11 patients were assigned to the HER2 0 group, 8 patients were assigned to the HER2 $1+$ group, and 12 
Citation: Tsuda B, Kametani Y, Miyamoto A, Miyako H, Kumaki N, et al. (2015) The Effect of Peptide Treatment on the HLA-Binding and Antibody Production in Peripheral Blood Mononuclear Cells Obtained from Japanese Breast Cancer Patients. J Vaccines Vaccin 6:

Page 4 of 8

patients were assigned to the HER2 $3+$ group. The lymph node nodes (N0) and 4 patients had metastasis in more than 1 lymph nodes metastasis data revealed that 27 patients had metastasis in lymph (N1; Table 1).

\begin{tabular}{|c|c|c|c|c|c|c|c|c|c|c|c|c|c|c|c|c|c|c|c|c|c|c|c|}
\hline No & $\begin{array}{l}\text { HER2 } \\
\text { expres } \\
\text { sion }\end{array}$ & $\begin{array}{l}\mathrm{Ag} \\
\mathrm{e}\end{array}$ & $\begin{array}{l}\text { Tumo } \\
\text { r size } \\
\text { (Invas } \\
\text { ive } \\
\text { lesion } \\
\text { ) }\end{array}$ & $\begin{array}{l}\text { Patholo } \\
\text { gical } \\
\text { type }\end{array}$ & $\begin{array}{l}\mathrm{N} \\
\text { sta } \\
\text { ge }\end{array}$ & $\begin{array}{l}A b \\
X \\
\text { tite } \\
r \\
(P \\
B S \\
)\end{array}$ & $\begin{array}{l}\text { Abx titer } \\
\text { (CH401M } \\
\text { AP) }\end{array}$ & HLA & & $\begin{array}{l}\text { SYF } \\
\text { THI }\end{array}$ & & $\begin{array}{l}\text { BIN } \\
\text { S }\end{array}$ & & HLA B & & $\begin{array}{l}\text { SYF } \\
\text { HI }\end{array}$ & PEIT & DRB1 & & $\begin{array}{l}\text { SYF } \\
\text { THI }\end{array}$ & & IED & \\
\hline 1 & $\mathrm{HD}$ & 27 & & & & $\begin{array}{l}1.3 \\
77\end{array}$ & 3.39 & $\begin{array}{l}A^{*} 26 \\
: 01\end{array}$ & $\begin{array}{l}\mathrm{A}^{*} 33 \\
: 03\end{array}$ & 0 & & & & $\begin{array}{l}B^{*} 40: 0 \\
2\end{array}$ & $\begin{array}{l}\mathrm{B}^{*} 44 \\
: 03\end{array}$ & 0 & & $\begin{array}{l}\text { DRB1* } \\
\text { 13:02 }\end{array}$ & $\begin{array}{l}\text { DRB1* } \\
16: 02\end{array}$ & & & $\begin{array}{l}2 . \\
4\end{array}$ & \\
\hline 2 & $\mathrm{HD}$ & 35 & & & & $\begin{array}{l}1.0 \\
32\end{array}$ & 2.289 & $\begin{array}{l}A^{*} 11 \\
: 01\end{array}$ & $\begin{array}{l}\mathrm{A}^{\star} 24 \\
: 02\end{array}$ & 17 & 12 & 2 & & $\begin{array}{l}B^{*} 15: 0 \\
7\end{array}$ & $\begin{array}{l}\mathrm{B}^{*} 67 \\
: 01\end{array}$ & & & $\begin{array}{l}\text { DRB1* } \\
\text { 04:06 }\end{array}$ & $\begin{array}{l}\text { DRB1* } \\
15: 01\end{array}$ & & 20 & & \\
\hline 3 & $\mathrm{HD}$ & 41 & & & & $\begin{array}{l}2.6 \\
53\end{array}$ & 2.08 & $\begin{array}{l}\mathrm{A}^{*} 02 \\
: 01\end{array}$ & $\begin{array}{l}\mathrm{A}^{*} 02 \\
: 06\end{array}$ & 20 & 0 & $\begin{array}{l}2 \\
8\end{array}$ & & $\begin{array}{l}B^{*} 13: 0 \\
1\end{array}$ & $\begin{array}{l}\mathrm{B}^{*} 15 \\
: 01\end{array}$ & & 11 & $\begin{array}{l}\text { DRB1* } \\
12: 02\end{array}$ & $\begin{array}{l}\text { DRB1* } \\
14: 54\end{array}$ & & & & \\
\hline 4 & $\mathrm{HD}$ & 27 & & & & $\begin{array}{l}2.9 \\
4\end{array}$ & 1.928 & $\begin{array}{l}A^{*} 24 \\
: 02\end{array}$ & $\begin{array}{l}\mathrm{A}^{*} 26 \\
: 03\end{array}$ & 12 & & & & $\begin{array}{l}\mathrm{B}^{*} 15: 0 \\
1\end{array}$ & $\begin{array}{l}\mathrm{B}^{*} 52 \\
: 01\end{array}$ & 11 & & $\begin{array}{l}\text { DRB1* } \\
14: 06\end{array}$ & $\begin{array}{l}\text { DRB1* } \\
15: 02\end{array}$ & & & & $\begin{array}{l}4 . \\
64\end{array}$ \\
\hline 5 & $\mathrm{HD}$ & 24 & & & & $\begin{array}{l}3.7 \\
89\end{array}$ & 3.167 & $\begin{array}{l}\mathrm{A}^{*} 02 \\
: 01\end{array}$ & $\begin{array}{l}\mathrm{A}^{*} 24 \\
: 02\end{array}$ & 20 & 12 & 8 & & $\begin{array}{l}\mathrm{B}^{*} 07: 0 \\
2\end{array}$ & $\begin{array}{l}\mathrm{B}^{*} 15 \\
: 01\end{array}$ & 13 & 11 & $\begin{array}{l}\text { DRB1* } \\
01: 01\end{array}$ & $\begin{array}{l}\text { DRB1* } \\
04: 06\end{array}$ & 18 & & & \\
\hline 6 & $\mathrm{HD}$ & 37 & & & & $\begin{array}{l}0.8 \\
77\end{array}$ & 2.251 & $\begin{array}{l}\mathrm{A}^{*} 02 \\
: 01\end{array}$ & $\begin{array}{l}\mathrm{A}^{*} 02 \\
: 06\end{array}$ & 20 & 0 & $\begin{array}{l}2 \\
8 \\
8\end{array}$ & & $\begin{array}{l}B * 39: 0 \\
1\end{array}$ & $\begin{array}{l}\mathrm{B}^{*} 51 \\
: 01\end{array}$ & 24 & 14 & $\begin{array}{l}\text { DRB1* } \\
15: 01\end{array}$ & - & 20 & & & \\
\hline 7 & $\mathrm{HD}$ & 22 & & & & $\begin{array}{l}1.2 \\
42\end{array}$ & 0.893 & $\begin{array}{l}\mathrm{A}^{*} 02 \\
: 06\end{array}$ & $\begin{array}{l}A^{*} 24 \\
: 02\end{array}$ & 0 & 12 & & & $\begin{array}{l}\mathrm{B}^{* 15: 1} \\
8\end{array}$ & $\begin{array}{l}\mathrm{B}^{*} 40 \\
: 02\end{array}$ & 0 & & $\begin{array}{l}\text { DRB1* } \\
\text { 04:01 }\end{array}$ & $\begin{array}{l}\text { DRB1* } \\
08: 02\end{array}$ & 28 & & & $\begin{array}{l}2 . \\
76\end{array}$ \\
\hline 8 & $\mathrm{HD}$ & 21 & & & & $\begin{array}{l}1.1 \\
66\end{array}$ & 2.499 & $\begin{array}{l}A^{*} 02 \\
: 06\end{array}$ & $\begin{array}{l}\mathrm{A}^{*} 24 \\
: 02\end{array}$ & 0 & 12 & & & $\begin{array}{l}\mathrm{B}^{*} 40: 0 \\
2\end{array}$ & $\begin{array}{l}\mathrm{B}^{*} 52 \\
: 01\end{array}$ & & & $\begin{array}{l}\text { DRB1* } \\
\text { 09:01 }\end{array}$ & $\begin{array}{l}\text { DRB1* } \\
15: 02\end{array}$ & & & & $\begin{array}{l}4 . \\
64\end{array}$ \\
\hline 9 & $\mathrm{HD}$ & 31 & & & & $\begin{array}{l}8.5 \\
42\end{array}$ & 4.659 & $\begin{array}{l}A^{*} 02 \\
: 07\end{array}$ & $\begin{array}{l}\mathrm{A}^{*} 11 \\
: 01\end{array}$ & 20 & 17 & & 2. & $\begin{array}{l}\mathrm{B}^{*} 40: 0 \\
2\end{array}$ & $\begin{array}{l}\mathrm{B}^{*} 46 \\
: 01\end{array}$ & 0 & & $\begin{array}{l}\text { DRB1* } \\
08: 03\end{array}$ & $\begin{array}{l}\text { DRB1* } \\
09: 01\end{array}$ & & & & \\
\hline 10 & $\mathrm{HD}$ & 42 & & & & $\begin{array}{l}6.4 \\
87\end{array}$ & 5.422 & $\begin{array}{l}A^{*} 02 \\
: 06\end{array}$ & $\begin{array}{l}\mathrm{A}^{*} 11 \\
: 01\end{array}$ & 0 & 17 & & 2. & $\begin{array}{l}\mathrm{B}^{*} 39: 0 \\
1\end{array}$ & $\begin{array}{l}\mathrm{B}^{*} 55 \\
: 02\end{array}$ & & & $\begin{array}{l}\text { DRB1* } \\
08: 02\end{array}$ & $\begin{array}{l}\text { DRB1* } \\
15: 01\end{array}$ & & 20 & & \\
\hline 11 & 0 & 74 & $10 \times 3$ & IDC & 0 & $\begin{array}{l}33 . \\
073\end{array}$ & 7.474 & $\begin{array}{l}A^{*} 26 \\
: 01\end{array}$ & $\begin{array}{l}A^{*} 31 \\
: 01\end{array}$ & 0 & 17 & & 6. & $\begin{array}{l}\mathrm{B}^{*} 07: 0 \\
2\end{array}$ & $\begin{array}{l}\mathrm{B}^{*} 40 \\
: 02\end{array}$ & 13 & 0 & $\begin{array}{l}\text { DRB1* } \\
01: 01\end{array}$ & $\begin{array}{l}\text { DRB1* } \\
04: 01\end{array}$ & 18 & 28 & & \\
\hline 12 & 0 & 47 & $10 \times 4$ & IDC & 0 & $\begin{array}{l}3.9 \\
07\end{array}$ & 4.024 & $\begin{array}{l}\mathrm{A}^{*} 02 \\
: 01\end{array}$ & $\begin{array}{l}A^{*} 26 \\
: 01\end{array}$ & 20 & 0 & $\begin{array}{l}2 \\
8 \\
8\end{array}$ & & $\begin{array}{l}B^{*} 35: 0 \\
1\end{array}$ & $\begin{array}{l}\mathrm{B}^{*} 40 \\
: 02\end{array}$ & & 0 & $\begin{array}{l}\text { DRB1* } \\
04: 05\end{array}$ & $\begin{array}{l}\text { DRB1* } \\
08: 02\end{array}$ & & & & $\begin{array}{l}2 . \\
76\end{array}$ \\
\hline 13 & 0 & 48 & & DCIS & 0 & $\begin{array}{l}6.3 \\
28\end{array}$ & 3.708 & $\begin{array}{l}\mathrm{A}^{*} 11 \\
: 01\end{array}$ & $\begin{array}{l}\mathrm{A}^{*} 24 \\
: 02\end{array}$ & 17 & 12 & 2 & & $\begin{array}{l}B^{*} 35: 0 \\
1\end{array}$ & $\begin{array}{l}\mathrm{B}^{*} 67 \\
: 01\end{array}$ & & & $\begin{array}{l}\text { DRB1* } \\
12: 01\end{array}$ & $\begin{array}{l}\text { DRB1* } \\
15: 01\end{array}$ & & 20 & & \\
\hline 14 & 0 & 48 & 4 & $\begin{array}{l}\text { DCIS mi } \\
\text { inva. }\end{array}$ & 0 & $\begin{array}{l}4.4 \\
95\end{array}$ & 3.476 & $\begin{array}{l}A^{*} 02 \\
: 10\end{array}$ & $\begin{array}{l}\mathrm{A}^{*} 24 \\
: 02\end{array}$ & & 12 & & & $\begin{array}{l}B^{*} 40: 0 \\
6\end{array}$ & $\begin{array}{l}\mathrm{B}^{*} 46 \\
: 01\end{array}$ & & & $\begin{array}{l}\text { DRB1* } \\
04: 05\end{array}$ & $\begin{array}{l}\text { DRB1* } \\
08: 03\end{array}$ & & & & \\
\hline 15 & 0 & 70 & $30 \times 15$ & IDC & 0 & $\begin{array}{l}3.2 \\
45\end{array}$ & 3.786 & $\begin{array}{l}\mathrm{A}^{*} 02 \\
: 01\end{array}$ & $\begin{array}{l}\mathrm{A}^{\star} 24 \\
: 02\end{array}$ & 20 & 12 & 8 & & $\begin{array}{l}B^{*} 13: 0 \\
1\end{array}$ & $\begin{array}{l}\mathrm{B}^{*} 15 \\
: 01\end{array}$ & & 11 & $\begin{array}{l}\text { DRB1* } \\
\text { 12:02 }\end{array}$ & $\begin{array}{l}\text { DRB1* } \\
15: 01\end{array}$ & & 20 & & \\
\hline 16 & 0 & 26 & $25 \times 25$ & IDC & 0 & $\begin{array}{l}13 . \\
779\end{array}$ & 12.706 & $\begin{array}{l}\mathrm{A}^{*} 02 \\
: 01\end{array}$ & $\begin{array}{l}\mathrm{A}^{*} 31 \\
: 01\end{array}$ & 20 & 17 & 2 & 3. & $\begin{array}{l}B^{*} 35: 0 \\
1\end{array}$ & $\begin{array}{l}\mathrm{B}^{*} 54 \\
: 01\end{array}$ & & & $\begin{array}{l}\text { DRB1* } \\
04: 03\end{array}$ & - & & & & \\
\hline 17 & 0 & 57 & $2 \times 3.3$ & IDC & 0 & $\begin{array}{l}16 . \\
207\end{array}$ & 14.181 & $\begin{array}{l}A^{*} 24 \\
: 02\end{array}$ & $\begin{array}{l}A^{*} 33 \\
: 03\end{array}$ & 12 & & & & $\begin{array}{l}\mathrm{B}^{*} 15: 0 \\
7\end{array}$ & $\begin{array}{l}\mathrm{B}^{*} 52 \\
: 01\end{array}$ & & & $\begin{array}{l}\text { DRB1* } \\
04: 03\end{array}$ & $\begin{array}{l}\text { DRB1* } \\
15: 02\end{array}$ & & & & $\begin{array}{l}4 . \\
64\end{array}$ \\
\hline 18 & 0 & 51 & $23 \times 20$ & IDC & 0 & $\begin{array}{l}15 . \\
598\end{array}$ & 12.941 & $\begin{array}{l}\mathrm{A}^{*} 11 \\
: 01\end{array}$ & $\begin{array}{l}\mathrm{A}^{*} 31 \\
: 01\end{array}$ & 17 & 17 & $\begin{array}{l}2 \\
4 \\
4\end{array}$ & 3. & $\begin{array}{l}B^{*} 35: 0 \\
1\end{array}$ & $\begin{array}{l}\mathrm{B}^{*} 40 \\
: 01\end{array}$ & 15 & 14 & $\begin{array}{l}\text { DRB1* } \\
08: 03\end{array}$ & $\begin{array}{l}\text { DRB1* } \\
11: 01\end{array}$ & & 24 & & $\begin{array}{l}4 . \\
33\end{array}$ \\
\hline
\end{tabular}


Citation: Tsuda B, Kametani Y, Miyamoto A, Miyako H, Kumaki N, et al. (2015) The Effect of Peptide Treatment on the HLA-Binding and Antibody Production in Peripheral Blood Mononuclear Cells Obtained from Japanese Breast Cancer Patients. J Vaccines Vaccin 6:

\begin{tabular}{|c|c|c|c|c|c|c|c|c|c|c|c|c|c|c|c|c|c|c|c|c|c|c|c|}
\hline 19 & 0 & 72 & $15 \times 22$ & IDC & 1 & $\begin{array}{l}17 . \\
539\end{array}$ & 13.779 & $\begin{array}{l}\mathrm{A}^{* 11} \\
: 01\end{array}$ & $\begin{array}{l}\mathrm{A}^{*} 24 \\
: 02\end{array}$ & 17 & 12 & $\begin{array}{l}2 \\
4 \\
4\end{array}$ & & $\begin{array}{l}\mathrm{B}^{*} 51: 0 \\
1\end{array}$ & $\begin{array}{l}B * 59 \\
: 01\end{array}$ & 14 & & $\begin{array}{l}\text { DRB1* } \\
04: 05\end{array}$ & $\begin{array}{l}\text { DRB1* } \\
09: 01\end{array}$ & & & & \\
\hline 20 & 0 & 74 & $30 \times 23$ & IDC & 1 & $\begin{array}{l}17 . \\
265\end{array}$ & 13.985 & $\begin{array}{l}A^{*} 31 \\
: 01\end{array}$ & - & 17 & & & & $\begin{array}{l}B^{*} 40: 0 \\
2\end{array}$ & $\begin{array}{l}B^{*} 51 \\
: 01\end{array}$ & 0 & 14 & $\begin{array}{l}\text { DRB1* } \\
11: 01\end{array}$ & $\begin{array}{l}\text { DRB1* } \\
14: 54\end{array}$ & 24 & & $\begin{array}{l}4 . \\
3 \\
3\end{array}$ & \\
\hline 21 & 0 & 45 & & DCIS & 0 & $\begin{array}{l}22 . \\
679\end{array}$ & 21.379 & $\begin{array}{l}\mathrm{A}^{* 11} \\
: 01\end{array}$ & $\begin{array}{l}\mathrm{A}^{*} 24 \\
: 02\end{array}$ & 17 & 12 & $\begin{array}{l}2 \\
4 \\
4\end{array}$ & & $\begin{array}{l}B^{*} 15: 0 \\
1\end{array}$ & $\begin{array}{l}B^{\star} 52 \\
: 01\end{array}$ & 11 & & $\begin{array}{l}\text { DRB1* } \\
01: 01\end{array}$ & $\begin{array}{l}\text { DRB1* } \\
15: 02\end{array}$ & 18 & & & $\begin{array}{l}4 . \\
64\end{array}$ \\
\hline 22 & $1+$ & 48 & $15 \times 13$ & IDC & 0 & $\begin{array}{l}8.2 \\
43\end{array}$ & 10.207 & $\begin{array}{l}\mathrm{A}^{*} 02 \\
: 06\end{array}$ & $\begin{array}{l}A^{*} 31 \\
: 01\end{array}$ & 0 & 17 & & & $\begin{array}{l}\mathrm{B}^{* 1} 15: 0 \\
1\end{array}$ & $\begin{array}{l}B^{*} 40 \\
: 06\end{array}$ & 11 & & $\begin{array}{l}\text { DRB1* } \\
04: 10\end{array}$ & $\begin{array}{l}\text { DRB1* } \\
15: 01\end{array}$ & & 20 & & \\
\hline 23 & $1+$ & 50 & $20 \times 10$ & ILC & 0 & $\begin{array}{l}8.0 \\
13\end{array}$ & 5.302 & $\begin{array}{l}A^{*} 24 \\
: 02\end{array}$ & - & 12 & & & & $\begin{array}{l}B^{*} 52: 0 \\
1\end{array}$ & $\begin{array}{l}B^{*} 54 \\
: 01\end{array}$ & & 14 & $\begin{array}{l}\text { DRB1* } \\
04: 05\end{array}$ & $\begin{array}{l}\text { DRB1* } \\
15: 02\end{array}$ & & & & $\begin{array}{l}4 . \\
64\end{array}$ \\
\hline 24 & $1+$ & 43 & & DCIS & 0 & $\begin{array}{l}18 . \\
784\end{array}$ & 13.611 & $\begin{array}{l}A^{* 11} \\
: 01\end{array}$ & $\begin{array}{l}\mathrm{A}^{\star} 24 \\
: 20\end{array}$ & 17 & & $\begin{array}{l}2 \\
\dot{4}\end{array}$ & & $\begin{array}{l}\mathrm{B}^{*} 40: 0 \\
1\end{array}$ & $\begin{array}{l}B^{*} 55 \\
: 02\end{array}$ & 14 & & $\begin{array}{l}\text { DRB1* } \\
\text { 04:05 }\end{array}$ & $\begin{array}{l}\text { DRB1* } \\
15: 01\end{array}$ & & 20 & & \\
\hline 25 & $2+$ & 40 & $10 \times 10$ & IDC & 0 & $\begin{array}{l}20 . \\
47\end{array}$ & 14.787 & $\begin{array}{l}\mathrm{A}^{*} 02 \\
: 01\end{array}$ & $\begin{array}{l}\mathrm{A}^{\star} 24 \\
: 02\end{array}$ & 20 & 12 & $\begin{array}{l}2 \\
8 \\
8\end{array}$ & & $\begin{array}{l}B^{*} 52: 0 \\
1\end{array}$ & $\begin{array}{l}B^{*} 55 \\
: 02\end{array}$ & & & $\begin{array}{l}\text { DRB1* } \\
12: 02\end{array}$ & $\begin{array}{l}\text { DRB1* } \\
15: 02\end{array}$ & & & & $\begin{array}{l}4 . \\
64\end{array}$ \\
\hline 26 & $1+$ & 46 & $4 \times 3$ & IDC & 1 & $\begin{array}{l}22 . \\
842\end{array}$ & 17.851 & $\begin{array}{l}A^{*} 24 \\
: 02\end{array}$ & $\begin{array}{l}\mathrm{A}^{*} 31 \\
: 01\end{array}$ & 12 & 17 & & $\begin{array}{l}3 . \\
6\end{array}$ & $\begin{array}{l}\mathrm{B}^{*} 40: 0 \\
1\end{array}$ & $\begin{array}{l}B^{*} 52 \\
: 01\end{array}$ & 14 & & $\begin{array}{l}\text { DRB1* } \\
\text { 09:01 }\end{array}$ & $\begin{array}{l}\text { DRB1* } \\
15: 02\end{array}$ & & & & $\begin{array}{l}4 . \\
64\end{array}$ \\
\hline 27 & $2+$ & 47 & & DCIS & 0 & $\begin{array}{l}13 . \\
479\end{array}$ & 13.444 & $\begin{array}{l}\mathrm{A}^{*} 02 \\
: 06\end{array}$ & $\begin{array}{l}A^{*} 11 \\
: 01\end{array}$ & 0 & 17 & & $\begin{array}{l}2 . \\
4\end{array}$ & $\begin{array}{l}B^{*} 35: 0 \\
1\end{array}$ & $\begin{array}{l}B^{*} 51 \\
: 01\end{array}$ & 15 & 14 & $\begin{array}{l}\text { DRB1* } \\
04: 05\end{array}$ & $\begin{array}{l}\text { DRB1* } \\
\text { 09:01 }\end{array}$ & & & & \\
\hline 28 & $1+$ & 46 & $10 \times 8$ & IDC & 0 & $\begin{array}{l}14 . \\
922\end{array}$ & 11.567 & $\begin{array}{l}\mathrm{A}^{*} 02 \\
: 06\end{array}$ & $\begin{array}{l}\mathrm{A}^{*} 24 \\
: 02\end{array}$ & 0 & 12 & & & $\begin{array}{l}\mathrm{B}^{*} 44: 0 \\
3: 01\end{array}$ & $\begin{array}{l}B^{*} 51 \\
: 01\end{array}$ & 15 & 14 & $\begin{array}{l}\text { DRB1* } \\
13: 02\end{array}$ & $\begin{array}{l}\text { DRB1* } \\
15: 01\end{array}$ & & 20 & $\begin{array}{l}2 . \\
4\end{array}$ & \\
\hline 29 & $1+$ & 46 & & DCIS & 0 & $\begin{array}{l}19 . \\
063\end{array}$ & 14.652 & $\begin{array}{l}\mathrm{A}^{*} 02 \\
: 01\end{array}$ & $\begin{array}{l}\mathrm{A}^{*} 24 \\
: 02\end{array}$ & 20 & 12 & $\begin{array}{l}2 \\
8 \\
8\end{array}$ & & $\begin{array}{l}B^{*} 35: 0 \\
1\end{array}$ & $\begin{array}{l}B^{*} 44 \\
\vdots \\
03: 0 \\
1\end{array}$ & 15 & & $\begin{array}{l}\text { DRB1* } \\
08: 02\end{array}$ & $\begin{array}{l}\text { DRB1* } \\
15: 01\end{array}$ & & 20 & $\begin{array}{l}2 . \\
7 \\
6\end{array}$ & \\
\hline 30 & $3+$ & 51 & $25 \times 20$ & IDC & 1 & $\begin{array}{l}7.6 \\
51\end{array}$ & 11.265 & $\begin{array}{l}\mathrm{A}^{* 11} \\
: 01\end{array}$ & $\begin{array}{l}\mathrm{A}^{*} 24 \\
: 02\end{array}$ & 17 & 12 & $\begin{array}{l}2 \\
. \\
4\end{array}$ & & $\begin{array}{l}B^{*} 07: 0 \\
2\end{array}$ & $\begin{array}{l}\mathrm{B}^{*} 67 \\
\vdots \\
01: 0 \\
1\end{array}$ & 13 & & $\begin{array}{l}\text { DRB1* } \\
01: 01\end{array}$ & $\begin{array}{l}\text { DRB1* } \\
15: 01\end{array}$ & 18 & 20 & & \\
\hline 31 & $3+$ & 41 & $15 \times 10$ & IDC & 0 & $\begin{array}{l}7.5 \\
87\end{array}$ & 10.121 & $\begin{array}{l}A^{*} 02 \\
: 01\end{array}$ & $\begin{array}{l}\mathrm{A}^{*} 24 \\
: 02\end{array}$ & 20 & 12 & $\begin{array}{l}2 \\
8 \\
8\end{array}$ & & $\begin{array}{l}B^{*} 35: 0 \\
1\end{array}$ & $\begin{array}{l}B^{*} 52 \\
: 01\end{array}$ & 15 & & $\begin{array}{l}\text { DRB1* } \\
04: 10\end{array}$ & $\begin{array}{l}\text { DRB1* } \\
15: 02\end{array}$ & & & & \\
\hline 32 & $3+$ & 65 & & DCIS & 0 & $\begin{array}{l}8.2 \\
8\end{array}$ & 10.963 & $\begin{array}{l}\mathrm{A}^{*} 11 \\
: 01\end{array}$ & $\begin{array}{l}\mathrm{A}^{\star} 24 \\
: 02\end{array}$ & 17 & 12 & $\begin{array}{l}2 \\
4 \\
4\end{array}$ & & $\begin{array}{l}B^{*} 13: 0 \\
1\end{array}$ & \begin{tabular}{|l}
$\mathrm{B}^{*} 48$ \\
$: 01$
\end{tabular} & & & $\begin{array}{l}\text { DRB1* } \\
12: 02\end{array}$ & $\begin{array}{l}\text { DRB1* } \\
14: 54\end{array}$ & & & & \\
\hline 33 & $3+$ & 61 & $15 \times 14$ & IDC & 0 & $\begin{array}{l}13 . \\
115\end{array}$ & 12.137 & $\begin{array}{l}A^{\star} 24 \\
: 02\end{array}$ & $\begin{array}{l}A^{*} 31 \\
: 01\end{array}$ & 12 & 17 & & $\begin{array}{l}3 . \\
6\end{array}$ & $\begin{array}{l}B^{*} 35: 0 \\
1\end{array}$ & $\begin{array}{l}B^{*} 51 \\
: 01\end{array}$ & 15 & 14 & $\begin{array}{l}\text { DRB1* } \\
04: 10\end{array}$ & $\begin{array}{l}\text { DRB1* } \\
09: 01\end{array}$ & & & & \\
\hline 34 & $3+$ & 64 & $40 \times 40$ & IDC & 0 & $\begin{array}{l}14 . \\
961\end{array}$ & 11.4 & $\begin{array}{l}\mathrm{A}^{*} 02 \\
: 06\end{array}$ & $\begin{array}{l}\mathrm{A}^{*} 24 \\
: 02\end{array}$ & 0 & 12 & & & $\begin{array}{l}\mathrm{B}^{*} 35: 0 \\
1\end{array}$ & $\begin{array}{l}B^{*} 54 \\
: 01\end{array}$ & 15 & & $\begin{array}{l}\text { DRB1* } \\
04: 05\end{array}$ & $\begin{array}{l}\text { DRB1* } \\
12: 01\end{array}$ & & & & \\
\hline 35 & $3+$ & 75 & $15 \times 15$ & IDC & 1 & $\begin{array}{l}13 . \\
117\end{array}$ & 9.002 & $\begin{array}{l}\mathrm{A}^{*} 02 \\
: 07\end{array}$ & $\begin{array}{l}A^{*} 11 \\
: 01\end{array}$ & & 17 & & $\begin{array}{l}2 . \\
4\end{array}$ & $\begin{array}{l}\mathrm{B}^{*} 39: 0 \\
1\end{array}$ & $\begin{array}{l}B^{*} 46 \\
: 01\end{array}$ & 24 & 15 & $\begin{array}{l}\text { DRB1* } \\
08: 03\end{array}$ & & & & & \\
\hline 36 & $3+$ & 61 & $10 \times 8$ & $\begin{array}{l}\text { DCIS mi } \\
\text { inva. }\end{array}$ & 0 & $\begin{array}{l}66 . \\
892\end{array}$ & 58.129 & $\begin{array}{l}A^{*} 02 \\
: 06\end{array}$ & $\begin{array}{l}A^{\star} 24 \\
: 02\end{array}$ & 0 & 12 & & & $\begin{array}{l}\mathrm{B}^{*} 37: 0 \\
1\end{array}$ & $\begin{array}{l}B^{\star} 52 \\
: 01\end{array}$ & & & $\begin{array}{l}\text { DRB1* } \\
\text { 10:01 }\end{array}$ & $\begin{array}{l}\text { DRB1* } \\
15: 02\end{array}$ & & & & $\begin{array}{l}4 . \\
64\end{array}$ \\
\hline 37 & $3+$ & 34 & & DCIS & 0 & $\begin{array}{l}84 . \\
442\end{array}$ & 47.877 & $\begin{array}{l}\mathrm{A}^{*} 02 \\
: 01\end{array}$ & $\begin{array}{l}\mathrm{A}^{*} 33 \\
: 03\end{array}$ & 20 & & $\begin{array}{l}2 \\
8 \\
8\end{array}$ & & $\begin{array}{l}B^{\star} 52: 0 \\
1\end{array}$ & $\begin{array}{l}B^{*} 54 \\
: 01\end{array}$ & & & $\begin{array}{l}\text { DRB1 } \\
04: 03\end{array}$ & $\begin{array}{l}\text { DRB1* } \\
15: 01\end{array}$ & & 20 & & \\
\hline 38 & $3+$ & 51 & $\begin{array}{l}2.5 \times 2 . \\
5\end{array}$ & IDC & 1 & $\begin{array}{l}13 . \\
779\end{array}$ & 15.666 & $\begin{array}{l}\mathrm{A}^{* 11} \\
: 01\end{array}$ & $\begin{array}{l}\mathrm{A}^{*} 24 \\
: 02\end{array}$ & 17 & 12 & $\begin{array}{l}2 \\
4 \\
4\end{array}$ & & $\begin{array}{l}B^{*} 51: 0 \\
1\end{array}$ & $\begin{array}{l}\mathrm{B}^{*} 59 \\
: 01\end{array}$ & 14 & & $\begin{array}{l}\text { DRB1* } \\
09: 01\end{array}$ & $\begin{array}{l}\text { DRB1* } \\
15: 01\end{array}$ & & 20 & & \\
\hline
\end{tabular}


Citation: Tsuda B, Kametani Y, Miyamoto A, Miyako H, Kumaki N, et al. (2015) The Effect of Peptide Treatment on the HLA-Binding and Antibody Production in Peripheral Blood Mononuclear Cells Obtained from Japanese Breast Cancer Patients. J Vaccines Vaccin 6: 270. doi:10.4172/2157-7560.1000270

Page 6 of 8

\begin{tabular}{|c|c|c|c|c|c|c|c|c|c|c|c|c|c|c|c|c|c|c|c|c|c|c|}
\hline 39 & $3+$ & 68 & $10 \times 9$ & IDC & 0 & $\begin{array}{l}18 . \\
271\end{array}$ & 15.564 & $\begin{array}{l}\mathrm{A}^{*} 02 \\
: 01\end{array}$ & $\begin{array}{l}A^{*} 33 \\
: 03\end{array}$ & 20 & & 2 & & $\begin{array}{l}B^{*} 15: 0 \\
1\end{array}$ & $\begin{array}{l}\mathrm{B}^{*} 51 \\
: 01\end{array}$ & 11 & 14 & $\begin{array}{l}\text { DRB1* } \\
04: 02\end{array}$ & $\begin{array}{l}\text { DRB1* } \\
08: 02\end{array}$ & & & $\begin{array}{l}2 . \\
76\end{array}$ \\
\hline 40 & $3+$ & 53 & $49 \times 20$ & IDC & 0 & $\begin{array}{l}21 . \\
52\end{array}$ & 16.309 & $\begin{array}{l}A^{*} 02 \\
: 06\end{array}$ & $\begin{array}{l}\mathrm{A}^{*} 31 \\
: 01\end{array}$ & 0 & 17 & & $\begin{array}{l}3 . \\
6\end{array}$ & $\begin{array}{l}B^{*} 15: 0 \\
1\end{array}$ & $\begin{array}{l}\mathrm{B}^{*} 40 \\
: 06\end{array}$ & 11 & & $\begin{array}{l}\text { DRB1* } \\
\text { 01:01 }\end{array}$ & $\begin{array}{l}\text { DRB1* } \\
08: 02\end{array}$ & 18 & & $\begin{array}{l}2 . \\
76\end{array}$ \\
\hline 41 & $3+$ & 75 & $80 \times 50$ & IDC & 0 & $\begin{array}{l}15 . \\
406\end{array}$ & 14.654 & $\begin{array}{l}A^{\star} 26 \\
: 01\end{array}$ & $\begin{array}{l}A^{*} 11 \\
: 01\end{array}$ & 0 & 17 & & $\begin{array}{l}3 . \\
6\end{array}$ & $\begin{array}{l}B^{*} 52: 0 \\
1\end{array}$ & $\begin{array}{l}B^{*} 54 \\
: 01\end{array}$ & & & $\begin{array}{l}\text { DRB1* } \\
12: 01\end{array}$ & $\begin{array}{l}\text { DRB1* } \\
15: 01\end{array}$ & & 20 & \\
\hline
\end{tabular}

Table 2: Clinical characteristics and HLA types.

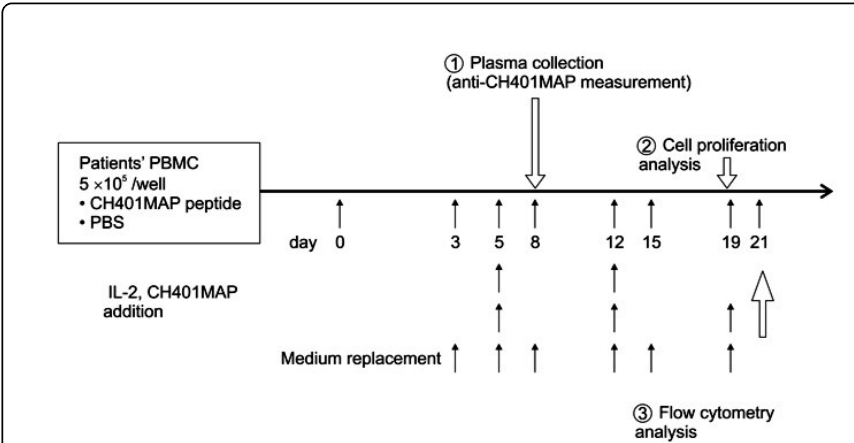

Figure 3: Protocol for peripheral blood mononuclear cell (PBMC) stimulation with CH401MAP.

Table $2 \mathrm{~A}$ and B summarizes the clinical characteristics and HLA types of all enrolled patients. As described in our previous study, HLApeptide binding affinity analyses were performed using SYFPEITHI, BIMAS, and IEDB databases. We set the cutoff value as 0 , and the patients' scores were distributed from 11 to 24 for SYFPEITHI and 2.4 to 3.6 for BIMAS, and 2.4 to 4.64 for IEDB. HLA class I class II alleles of all patients and HDs were predicted to have some affinity with CH401MAP (Table 2A and 2B). Moreover, as shown in our previous study, CH401MAP stimulation induced significantly higher cell proliferation of PBMCs isolated from the breast cancer groups than that of PBMCs isolated from HDs (data not shown).

\section{Anti-CH401MAP antibody production}

The experimental set-up for the in vitro cell culture of the PBMCs is summarized in Figure 2. Based on the HER2 expression levels, the cell samples were assigned to one of the three experimental groups. PBMCs were stimulated with the peptide, and the anti-peptide antibody production was evaluated. A comparative analysis of the levels of secreted anti-CH401MAP antibody produced by stimulated and unstimulated PBMCs was performed to identify significant differences. Mean scores of the concentration of anti-CH401MAP antibody secreted in the absence of peptide stimulation were as follows: HD control group, 3.01; HER2 0 group, 14.01; HER2 1+, $2+$ group, 15.727; and HER2 3+ group, 23.752 (Figure 4A). Mean scores of the concentration of anti-CH401MAP antibody secreted after CH401MAP stimulation were obtained by ELISA were as follows: HD control group, 2.858; HER2 0 group, 10.131; HER2 1+, 2+ group, 12.678; HER2 3+ group, 19.424 (Figure 4B). All scores were obtained by determining the antibody concentration $(\mathrm{pg} / \mathrm{ml})$ by using ELISA. There were not significantly differences between peptide-stimulated and unstimulated PBMCs for the concentration of anti-CH401MAP antibody levels. Table 2 summarizes the antibody production by PBMCs obtained from HD group and the 3 patient groups. Notably, the antibody titer of supernatants was significantly increased in PBMCs from the 3 patient groups compare to HD group.

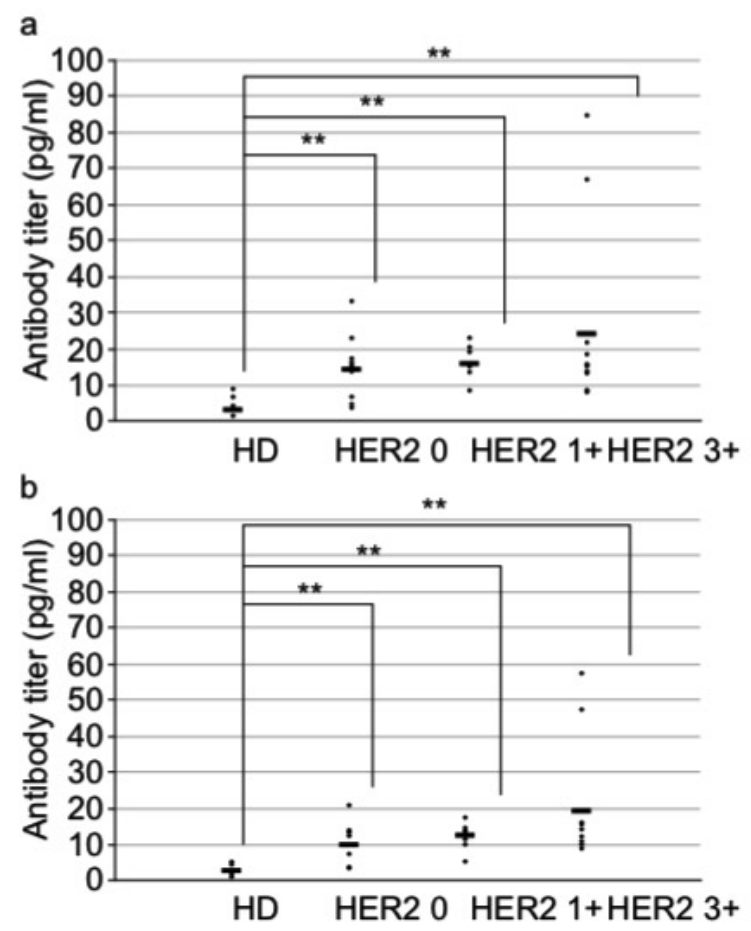

Figure 4: Anti-CH401MAP antibody titer of supernatants obtained from peptide-stimulated PBMCs.Antibody titers $(\mathrm{pg} / \mathrm{ml})$ of the 3 patient groups (HER2 0, HER2 $1+2+$, and HER2 $3+$ ) and the healthy donor group (HD) are shown. Horizontal lines represent the mean titer of the groups and the dots represent individual sample titer. (A) Non-stimulated culture series and (B) CH104MAP-stimulated culture series.

The following were assessed without CH401MAP stimulation. In the HD group, the concentration of the antibodies was lower than 10 $\mathrm{pg} / \mathrm{ml}$.

The samples were assigned to low $(<10 \mathrm{pg} / \mathrm{ml})$, intermediate $(11 \sim 59$ $\mathrm{pg} / \mathrm{ml})$, or high $(>60 \mathrm{pg} / \mathrm{ml})$ antibody titer groups based on the antibody production data. Most samples from the HER2 0 group were assigned to the low reaction group or the intermediate reaction group because the mean antibody titer was $10 \mathrm{pg} / \mathrm{ml}$. The HER2 0 group 
Citation: Tsuda B, Kametani Y, Miyamoto A, Miyako H, Kumaki N, et al. (2015) The Effect of Peptide Treatment on the HLA-Binding and Antibody Production in Peripheral Blood Mononuclear Cells Obtained from Japanese Breast Cancer Patients. J Vaccines Vaccin 6: 270. doi: $10.4172 / 2157-7560.1000270$

Page 7 of 8

included 4 samples that were assigned to the low reaction group and 7 samples that were assigned to the intermediate reaction group. However, the tumor size, histological type, and lymph node metastases data did not correlate with the antibody titer data in association with clinical information. In contrast, the HER2 $1+$ group included 1 sample that was assigned to the low reaction group and 7 samples that were assigned to the intermediate reaction group. The HER2 $3+$ group included 3 samples in the low reaction group, 7 in the intermediate reaction group, and 2 in the over $60 \mathrm{pg} / \mathrm{ml}$ antibody titer group, which is a high reaction group.

Two PBMC samples produced notably high levels of antibody titers. An antibody titer of $66.89 \mathrm{pg} / \mathrm{ml}$ was produced by PBMCs obtained from patient 36, a 61-year-old woman with tumor sized $10 \mathrm{~mm} \times 8$ $\mathrm{mm}$ and with DCIS with microinvasion. However, the peptide-HLA binding affinity was low. Similarly, PBMCs from case 27 also produced a high antibody titer of $84.442 \mathrm{pg} / \mathrm{ml}$. The patient was a 34-year -old woman with DCIS and had an intermediate HLA binding affinity score.

The CH401MAP-stimulated PBMC data indicate that the antiCH401MAP antibody titers of all breast cancer groups were significantly higher than those of the HD group. Even if there was no CH401MAP stimulation, antibody production was confirmed. In addition, no significant differences were noted in antibody production in the 4 samples after peptide stimulation, including in the low reaction group in HER2 0 group and HD $(p=0.189)$. However, the antibody production was significantly increased in the supernatants of PBMCs obtained from 2 cases from the low reaction group in HER2 1+ group, 3 cases from the low reaction group in HER2 3+ group, and all samples included in the HD group $(\mathrm{p}<0.001)$.

\section{Discussion}

Peptides with anticancer activities have been studied to develop "peptide vaccines." Currently, several peptide vaccines are available for breast cancer treatment as well as for many other types of cancer [1]. For example, peptides with anti-breast cancer activities, such as GP2, E75 and AE37, were successfully introduced into clinical trials $[5,6,16]$. However, these peptide vaccines for breast cancer have been designed to target only the peptide-specific CTLs that recognize tumor cells presenting themselves on HLA class I molecules. We previously reported a 20-mer peptide containing a B cell receptor epitope of antiHER2 monoclonal antibody "CH401", which was reported to have apoptotic anticancer activity [16] and it is a unique peptide because it can bind both HLA class I and class II molecule in a very short sequence and can induce not only helper $\mathrm{T}$ cell activation but also specific antibody production and cytotoxic $\mathrm{T}$ cell infiltration into HER2 positive tumors in the BALB/c mouse system [9]. The predictive peptide affinity analysis performed in this study also revealed that CH401MAP may have moderate to high affinity for all haplotypes of breast cancer patients. The predicted binding affinity was further validated by the scores calibrated by SYFPEITHI, BIMAS, and IEDB simulation algorithms. In this study, we also reported that peptide stimulation increased lymphocyte proliferation and the numbers of activated CD4 and CD8 T lymphocytes [15]. The increased cell numbers were also associated with HER2 expression levels in the tumor cells. The experimental procedure of the previous study was identical to that used in this study (Figure 2). In addition, similar to our previous experimental design, including lymphocyte proliferation reaction and analysis of cell surface marker (CD4, CD8, and CD25), were performed. Similar results were obtained from both studies (data not shown; [15]).

We showed that low level of anti-CH401MAP antibodies were produced by both CH401MAP-stimulated and unstimulated PBMCs from the HD group. The median antibody titer of PBMCs from all 3 breast cancer patients groups (classified by HER2 expression level) was significantly higher than that of PBMCs of the HD group (Figure 2A).

Samples from the HD group that produced anti-CH401MAP antibody with concentrations of approximately $10 \mathrm{pg} / \mathrm{ml}$ were classified as the low-reaction group. As HER2 expression levels increased, the antibody concentrations also tended to increase. As a result, the level of anti-CH401MAP antibody produced by PBMCs of all breast cancer groups (except the low-reaction group in the HER2 0 group) was significantly higher than that produced by PBMCs from the HD group. However, increased anti-CH401MAP antibody concentration was not associated with large tumors or lymph node metastasis found in advanced or high-risk breast cancers, including high HER2-expressing cancers. In addition, CH401MAP antibody concentration showed no association with the peptide-HLA binding scores. These results suggest that although the PBMC of Japanese breast cancer patients possess the potential of anti-CH401MAP antibody secretion, it is not closely correlated with the peptide stimulation, tumor mass or metastasis.

As we previously reported [9], the peptide can induce Her2 specific antibodies. Therefore, the difference is considered not to be the detection of nonspecific antibodies. Although the reason why the correlation is not observed in our results is not clear, it is conceivable that the patients groups we selected contained the overlapping groups of immunological states. We selected the patients only with no history of malignant disease in the past. Therefore, infiltrating cancer and non-infiltrating cancer may be involved in our group. The category of advanced and non-advanced cancer may show more clear difference because the advanced group may induce lower immune response.

Another possibility is, the difference of IHC and ELISA. The sensitivity of ELISA is higher than IHC. Moreover, ELISA can detect the past existence of the antigen, because the memory of the antibody secretion lasts for long time. Thus, even if the existence of the HER2 molecule cannot be detected by IHC, the HER2 expression history may be easily detected by this system. If we validate the ELISA level of HER2 antibody, it may become another powerful tool of diagnosis, especially for the progressive recurring breast cancer.

The third possibility could be the existence of HER2 carboxy terminal fragments, termed "p95". Till now, we cannot verify the existence of p95. However, the existence of p95 could limit the effectiveness of HER2 peptide vaccine, because the anti-CH401MAP antibodies might react with the secreted p95. If anti-CH401MAP reacts with $\mathrm{p} 95$, this antibody could be used to detect the presence of p95. This finding may be used to design treatment strategies for resistant HER2-expressing cancers (Figure 5). Normal HER2 has binding domains for both trastuzumab and $\mathrm{CH} 401$. In the absence of an extracellular binding domain on the HER2 molecule, trastuzumab binding is hindered in the secreted forms, such as p95; however, $\mathrm{CH} 401$ could still potentially bind to these forms because the $\mathrm{CH} 401$ binding domain occurs at the $\mathrm{N}$-terminal region. Pertuzumab, a molecular target drug, binds to the different site of HER2 from trastuzumab, and is shown to have additive effect in anti-cancer therapy, suggesting that similar effect may be induced by CH401MAPinduced antibodies. 
Citation: Tsuda B, Kametani Y, Miyamoto A, Miyako H, Kumaki N, et al. (2015) The Effect of Peptide Treatment on the HLA-Binding and Antibody Production in Peripheral Blood Mononuclear Cells Obtained from Japanese Breast Cancer Patients. J Vaccines Vaccin 6: 270. doi:10.4172/2157-7560.1000270

Page 8 of 8

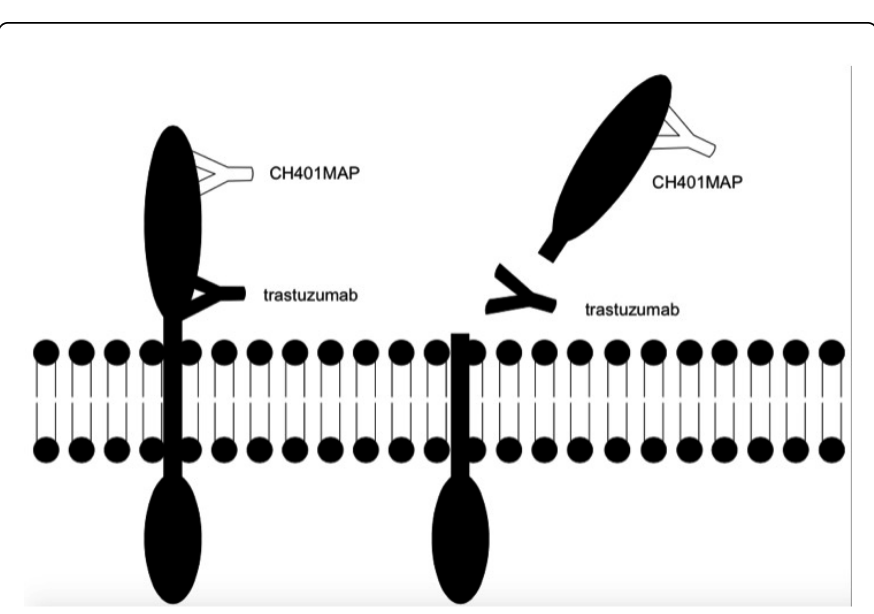

Figure 5: Trastuzumab and CH401MAP binding motif of HER2 molecule on the surface of cancer cells.

The ability to detect and induce anti-HER2 antibodies in breast cancer patients may become a powerful tool for the diagnosis and treatment of HER2-expressing breast cancer in future.

\section{Acknowledgements}

We are grateful to Yuko Okudaira for the excellent technical support. This work was supported by JSPS KAKENHI (Grant Number 25861165, 2013, and 2014), Tokai University School of Medicine Research Aid, and the 2012-2016 MEXT-Supported Program for the Strategic Research Foundation at Private Universities.

\section{References}

1. Song YC, Liu HH, Chen IH, Chen HW, Chong P, et al. (2014) A purified recombinant lipopeptide as adjuvant for cancer immunotherapy. BioMed research international 2014: 349783 .

2. Soliman H (2010) Developing an effective breast cancer vaccine. Cancer control 17: 183-190.

3. Comber JD, Philip R (2014) MHC class I antigen presentation and implications for developing a new generation of therapeutic vaccines. Ther Adv Vaccines 2: 77-89.

4. Shastri N, Schwab S, Serwold T (2002) Producing nature's gene-chips: the generation of peptides for display by MHC class I molecules. Annu Rev Immunol 20: 463-493.
5. Carmichael MG, Benavides LC, Holmes JP, Gates JD, Mittendorf EA, et al. (2010) Results of the first phase 1 clinical trial of the HER-2/neu peptide (GP2) vaccine in disease-free breast cancer patients: United States Military Cancer Institute Clinical Trials Group Study I-04. Cancer 116: 292-301.

6. Mittendorf EA, Clifton GT, Holmes JP, Clive KS, Patil R, et al. (2012) Clinical trial results of the HER-2/neu (E75) vaccine to prevent breast cancer recurrence in high-risk patients: from US Military Cancer Institute Clinical Trials Group Study I-01 and I-02. Cancer 118: 2594-2602.

7. Sette A, Sidney J (1999) Nine major HLA class I supertypes account for the vast preponderance of HLA-A and -B polymorphism. Immunogenetics 50: 201-212.

8. Hasegawa K, Noguchi Y, Koizumi F, Uenaka A, Tanaka M, et al. (2006) In vitro stimulation of CD8 and CD4 T cells by dendritic cells loaded with a complex of cholesterol-bearing hydrophobized pullulan and NYESO-1 protein: Identification of a new HLA-DR15-binding CD4 T-cell epitope. Clin Cancer Res 12: 1921-1927.

9. Miyako H, Kametani Y, Katano I, Ito R, Tsuda B, et al. (2011) Antitumor effect of new HER2 peptide vaccination based on B cell epitope. Anticancer Res 31: 3361-3368.

10. Kametani Y, Shiina M, Katano I, Ito R, Ando K, et al. (2006) Development of human-human hybridoma from anti-Her-2 peptideproducing $\mathrm{B}$ cells in immunized NOG mouse. Exp Hematol 34: 1240-1248.

11. Rammensee H, Bachmann J, Emmerich NP, Bachor OA, Stevanovic S (1999) SYFPEITHI: database for MHC ligands and peptide motifs. Immunogenetics 50: 213-219.

12. Parker KC, Bednarek MA, Coligan JE (1994) Scheme for ranking potential HLA-A2 binding peptides based on independent binding of individual peptide side-chains. J Immunol 152: 163-175.

13. Peters B, Sidney J, Bourne P, Bui HH, Buus S, et al. (2005) The immune epitope database and analysis resource: from vision to blueprint. PLoS biol 3: e91.

14. Wolff AC, Hammond ME, Hicks DG, Dowsett M, McShane LM, et al. (2013) Recommendations for human epidermal growth factor receptor 2 testing in breast cancer: American Society of Clinical Oncology/College of American Pathologists clinical practice guideline update. Journal of clinical oncology 31: 3997-4013.

15. Banri Tsuda YK, Yumiko Goto, Yuki Saito, Yasuhiro Suzuki, Sonoko Habu, et al. (2012) A Human B cell Receptor Epitope-Based erbB-2 Peptide (N:163-182) with Pan-Reactivity to the T cells of Japanese Breast Cancer Patients. J Vaccines Vaccin 3.

16. Ishida T, Tsujisaki M, Hinoda Y, Imai K, Yachi A (1994) Establishment and characterization of mouse-human chimeric monoclonal antibody to erbB-2 product. Jpn J Cancer Res 85: 172-178. 